A metodologia sistêmica na geografia agrária: um estudo sobre a territorialização dos assentamentos rurais Flamarion Dutra Alves, Vicente Celestino Pires Silveira

\title{
A METODOLOGIA SISTÊMICA NA GEOGRAFIA AGRÁRIA: UM ESTUDO SOBRE A TERRITORIALIZAÇÃO DOS ASSENTAMENTOS RURAIS
}

\section{The systemic methodology in agrarian geography: a study on the territorialization of the rural settlements}

\author{
Flamarion Dutra Alves \\ Doutorando em Geografia pela UNESP - Campus Rio Claro \\ dutrasm@yahoo.com.br
}

Vicente Celestino Pires Silveira

Prof. Dr. do Departamento de Educação Agrícola e Extensão Rural - Centro de Ciências Rurais da UFSM

Artigo recebido para publicação em 12/04/2007 e aceito para publicação em 25/02/2008

RESUMO: Este artigo tem como objetivo demonstrar a importância da metodologia sistêmica em pesquisas nas Ciências Humanas, em especial na Geografia Agrária, através da avaliação das alterações socioeconômicas e territoriais dos assentamentos rurais. $O$ artigo foi divido em partes, primeiro foi realizado um estudo teórico da metodologia sistêmica e em seguida, a aplicação dessa metodologia para avaliar os impactos da territorialização dos assentamentos rurais, na organização espacial de Candiota no estado do Rio Grande do Sul.

Palavras-chave: Metodologia sistêmica. Assentamentos rurais. Territorialização. Candiota - RS.

ABSTRACT: This paper has as objective to demonstrate to the importance of the systemic methodology in research in Sciences Human beings, in special in Agrarian Geography, through the evaluation of the socialeconomical and territorial alterations of the rural settlements. The paper was divides in parts, first was carried through a theoretical study of the systemic methodology and after that, the application of this methodology to evaluate the impacts of the territorialization of the rural settlements, in the space organization of Candiota County in the state of the Rio Grande do Sul.

Keywords: Systemic Methodology. Rural Settlements. Territorialization, Candiota.

\section{INTRODUÇÃO}

Ao pesquisar realidades cada vez mais dinâmicas e complexas se faz necessário aplicar instrumentos de análises que permitam abordar uma gama de aspectos, informações e suas inter-relações. Para avaliar as alterações socioeconômicas e territoriais decorrentes das implementações dos assentamentos rurais buscou-se uma metodologia que permitiu uma observação do todo, dos elementos que o compõem e as inter-relações entre esses elementos.

A ocupação populacional, realizada em um espaço, trás mudanças de diversas ordens, seja social, econômica, cultural ou política, tais processos de transformações do espaço são conseqüências de diversos 
motivos, que nem sempre são analisados sistemicamente. O resgate histórico vem contribuir para a verificação das origens das transformações, juntamente com diversas variáveis que contribuem para a alteração de um espaço.

A territorialização dos assentamentos rurais gera diferentes impactos no espaço conquistado. Nesse sentido, a utilização da metodologia sistêmica busca compreender os fatores históricos, questões sociais, econômicas, políticas, culturais, ambientais, e as inter-relações entre os elementos e suas disputas internas no sistema, onde os fenômenos devem ser estudados dentro de um contexto e não de forma isolada e separada.

Sendo assim, através da metodologia sistêmica, fundamentada em Bertalanffy (1975) e Morin (1977) se consegue atingir os objetivos propostos na avaliação das alterações dos assentamentos rurais na dinâmica territorial no município de Candiota - RS (Mapa 1), que apresenta vinte e cinco assentamentos, com 693 famílias, ocupando uma área de 17.634 ha.

Assim, a primeira parte do artigo abordará, brevemente, uma discussão teórico-conceitual da metodologia sistêmica e suas aplicações nas ciências humanas, dando ênfase a sua aplicação nos assentamentos rurais. Em seguida, será trabalhado o procedimento metodológico adotado na elaboração da pesquisa em assentamentos rurais e por fim, o resultado e discussão da aplicação da metodologia sistêmica na organização espacial do município de Candiota - RS.

Deve ficar claro que este artigo tem a intenção de mostrar mais uma ferramenta para o estudo das alterações socioterritoriais dos assentamentos rurais. Na medida em que as transformações do território ficam cada vez mais dinâmicas e complexas, há que se ter um método claro que identifique o maior número de elementos e inter-relações que compõem o sistema em estudo.

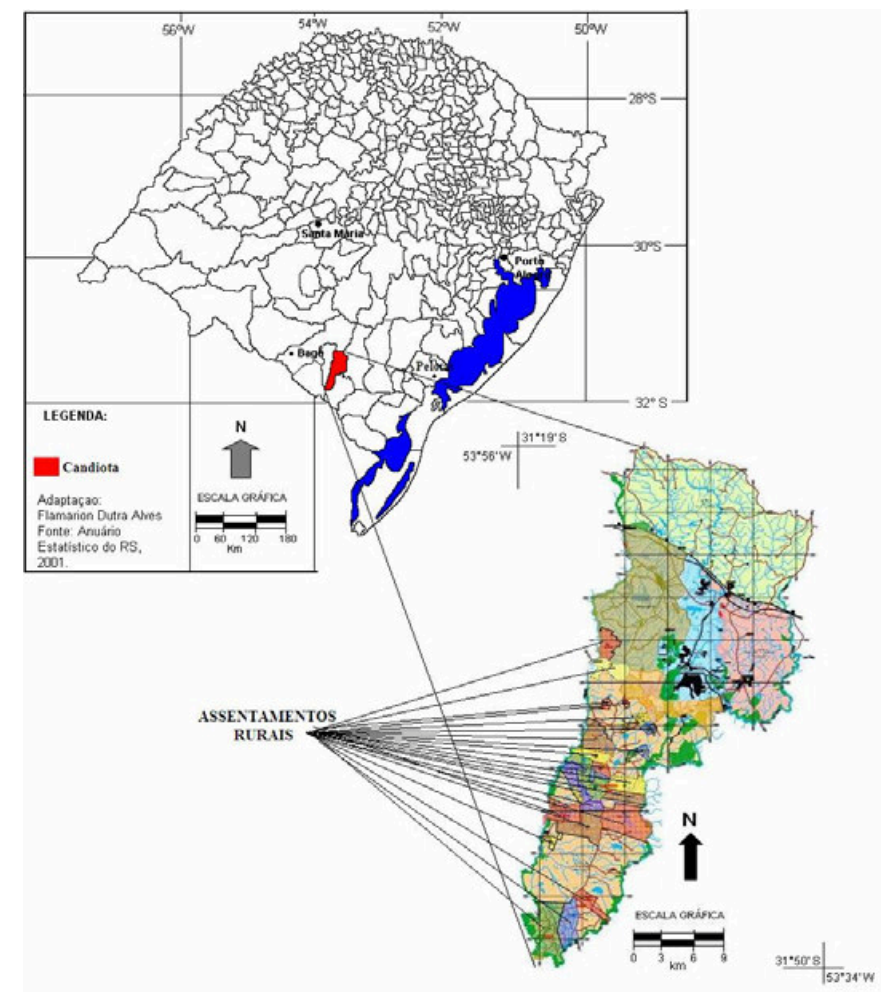

Mapa 1. Mapa da localização de Candiota - RS e dos assentamentos rurais. Organização: Flamarion Dutra Alves. 


\section{A METOdOLOGIA SISTÊMiCA NAS CIÊNCIAS HUMANAS}

A utilização da metodologia sistêmica é fundamental para a compreensão dos diversos fenômenos da sociedade. Sua origem data do ano de 1945 com a Teoria Geral dos Sistemas (TGS) de autoria de Ludwig von Bertalanffy (1901-1972); essa teoria foi reforçada e bastante utilizada na II Guerra Mundial, quando as equipes trabalhavam, interdisciplinarmente, com profissionais de várias áreas do conhecimento, para solucionar os complexos problemas daquele período. Nesse contexto, a TGS emergiu como uma ferramenta adequada para lidar com as diversas complexidades e as idéias comuns às várias áreas do conhecimento.

Para diagnosticar a realidade humana a ciência precisa de um enfoque sistêmico, devido a duas grandes mudanças ocorridas na sociedade contemporânea. Face a essas mudanças surge a necessidade desse enfoque. Bertalanffy (1975) explanou sobre essas duas mudanças:

Uma é o desenvolvimento tecnológico, que permite um domínio da natureza nunca antes realizado, e deveria abrir caminho para aliviar a fome, doença, a superpopulação, etc. a que a humanidade esteve anteriormente exposta. O outro fator é a natureza global de nossa civilização. As anteriores eram limitadas por fronteiras geográficas e compreendiam somente grupos limitados de seres humanos (BERTALANFFY, 1975, p. 271).

Dentro dessa realidade, muda-se o padrão das análises que antes eram feitas em categorias separadas e isoladas (Figura 1). Conforme afirmou Bertalanffy (1975, p.71) a "ciência parecia ser analítica, isto é, a divisão da realidade em unidades cada vez menores e o isolamento de cadeias causais individuais". Isso fez com que se pensasse em um método que mudasse a forma de pesquisar o mundo, uma forma global que vislumbrasse o todo.

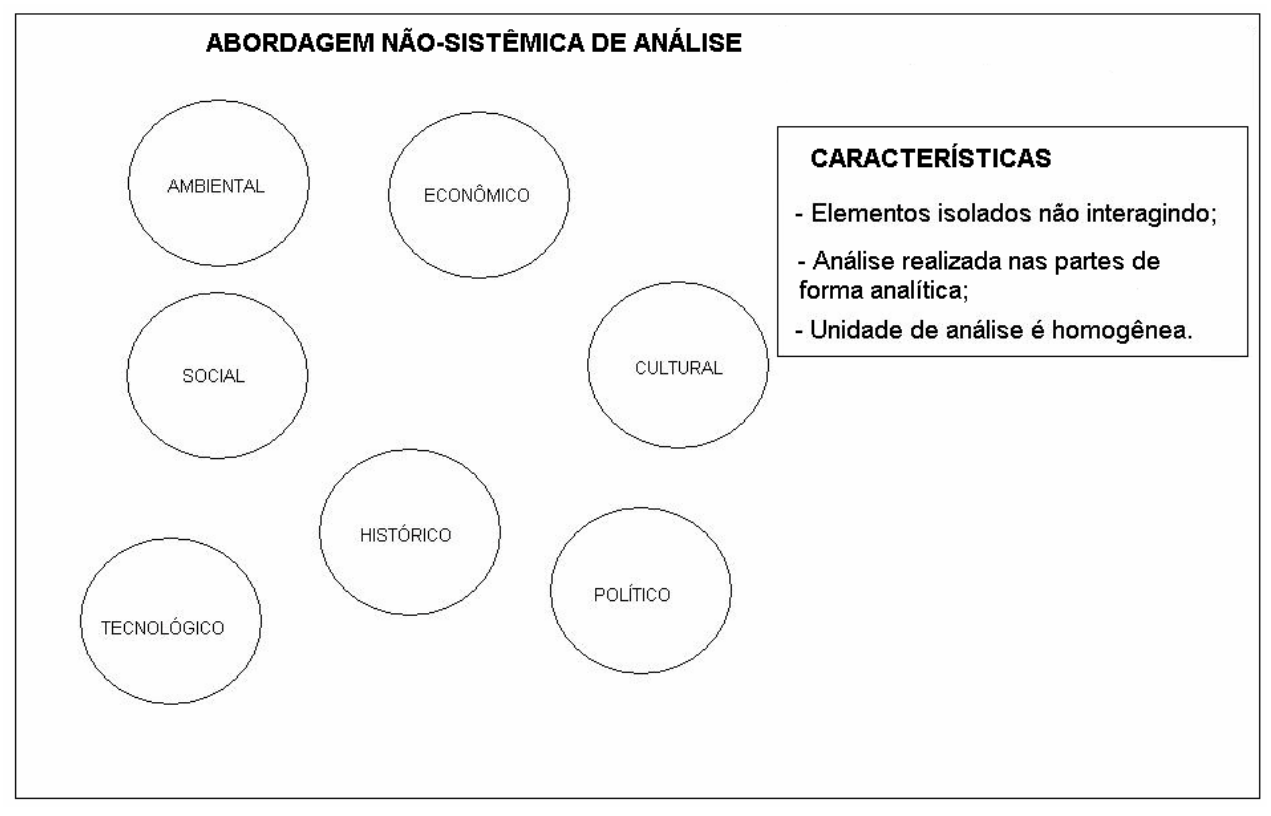

Figura 1 - Abordagem não-sistêmica de análise.

Organização: Flamarion Dutra Alves.

A sociedade precisa entender as várias interrelações existentes entre seus elementos e fatores que a modificam, pois a organização do espaço - objeto de estudo da Geografia - nada mais é do que a 
conjugação do geossitema natural com o sistema antrópico ou socioeconômico. Nessa perspectiva a teoria de Bertalanffy (1975) na qual se baseia em um método de análise sistêmico, integrando as partes, propicia ao geógrafo apreender seu objeto de estudo. Assim,

[...] A tendência ao estudar os sistemas como uma entidade e não como um aglomerado de partes está de acordo com a tendência da ciência contemporânea que não isola mais os fenômenos em contextos estreitamente confinados, mas abrese ao exame das interações e investiga setores da natureza cada vez maiores (ACKOFF, 1959 apud BERTALANFFY, 1975, p.25).

A partir dessas mudanças no enfoque do método de investigação, esta pesquisa norteia-se pela metodologia sistêmica que busca a análise de diversas categorias em forma integrada (Figura 2). Cada elemento apresenta vários sub-sistemas, e esses devem ser analisados entre si em simultaneidade, suas interferências mútuas e suas ligações. A ação de um sub-sistema pode provocar uma reação em outro subsistema, direta ou indiretamente que por sua vez recebe influência de outro sub-sistema de seus elementos ou de outro elemento.

O sistema é composto por elementos ou também chamados de unidades que estão em constante transformação ou em processo de formação, essa metamorfose ou morfogênese dos elementos são denominados por organização Os elementos interagem entre si, em um processo de trocas ou de lutas. Essa dinâmica dentro do sistema é denominada de inter-relações.

Ao analisar o objeto de estudo deve-se discutilo a partir do todo, para isso é fundamental verificar as interações existentes entre os elementos, conforme Morin (1977, p. 101) "A idéia de inter-relação remete para os tipos e as formas de ligação entre elementos ou indivíduos, entre estes elementos / indivíduos e o todo". Assim, o sistema é uma "unidade global organizada de inter-relações entre elementos, ações ou indivíduos" (Morin, 1977, p.100).

Cada unidade do sistema recebe uma imposição, restrições ou sujeições para seu desempenho total. Essas advertências fazem com que os elementos percam ou inibam suas qualidades ou propriedades (MORIN, 1977).

Assim, a metodologia sistêmica baseia-se na análise do processo de organização de cada elemento e nas inter-relações entre eles, ou seja, a idéia do todo passa pelas riquezas das interconexões, das interfaces entre os elementos, e não do número de elementos, não sendo um mero agregado, amontoado ou soma de partes. Desse modo, Bertalanffy (1975) descreveu em sua Teoria Geral dos Sistemas que é

Necessário estudar não somente partes e processos isoladamente, mas também resolver os decisivos problemas encontrados na organização e na ordem que os unifica, resultante da interação dinâmica das partes, tornando o comportamento das partes diferente quando estudado isoladamente e quando tratado no todo (BERTALANFFY, 1975, p.53).

Sociedade \& Natureza, Uberlândia, 20 (1): 125-137, jun. 2008 


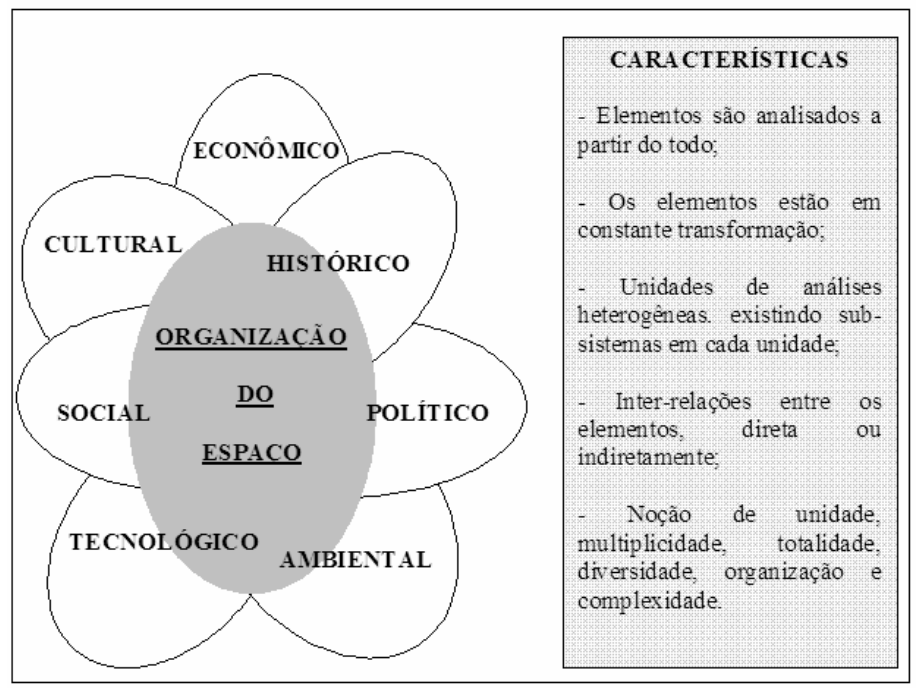

Figura 2 - Abordagem sistêmica ou enfoque sistêmico de análise.

Organização: Flamarion Dutra Alves.

Bertalanffy ainda descreve o sistema como sendo uma "totalidade que se baseia na competição entre os seus elementos e pressupõe a luta entre as suas partes" (BERTALANFFY, 1968, p.66 apud MORIN, 1977, p. 117).

O sistema é complexo devido às suas interconexões. Nesse sentido, Morin afirma que

A complexidade surge, portanto no seio do uno ao mesmo tempo como relatividade, relacionalidade, diversidade, alteridade, duplicidade, ambigüidade, incerteza, antagonismo, e na união destas noções que são umas em relação às outras, complementares, concorrentes e antagônicas (MORIN, 1977, p.141).
Morin (1977) trabalhou com a tese da análise sistêmica para os diversos fenômenos da natureza, sendo esses de ordem (econômica, ambiental, cultural, social, política etc) e propôs que os elementos não devem ser analisados de forma isolada uns dos outros e sim nas suas inter-relações, pois há uma complexidade organizada entre os elementos.

Na Geografia Agrária, Diniz (1984) trabalhou com o enfoque sistêmico para diagnosticar a realidade agrícola e entender as dinâmicas no espaço agrário através de tipologias e regionalizações (Figura 3). O uso dessa metodologia auxilia na compreensão das diversas interações entre os elementos que compõem os sistemas estudados.

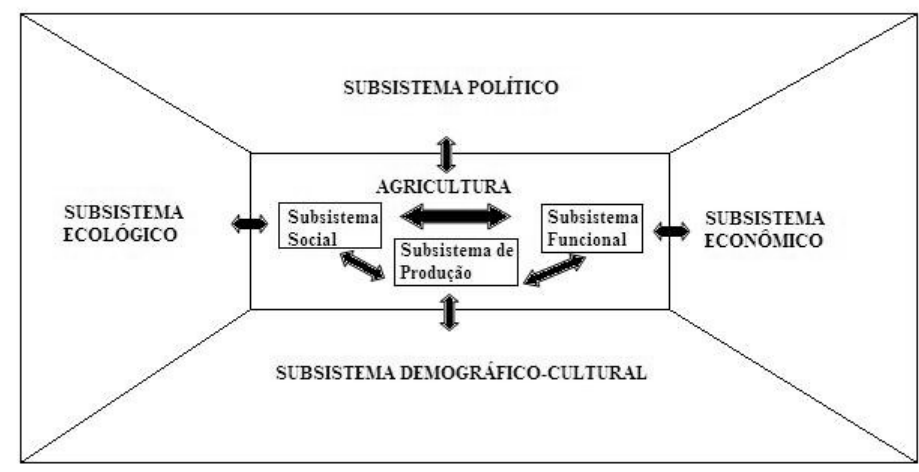

Figura 3 - Sistema da Agricultura: subsistemas internos e externos, conforme a Comissão de Tipologia Agrícola.

Fonte: Diniz (1984). 
O modelo adotado por Diniz (1984) visa entender os sub-sistemas internos e externos da agricultura, onde a questão da produção agrícola está no interior do sistema e os elementos socioeconômicos, culturais e ambientais estão no subsistema externo.

Por esses motivos vistos, a utilização da metodologia sistêmica é peça-chave para o conhecimento da realidade de uma sociedade, pois os conhecimentos globais e históricos são importantes para a análise local de um município. No caso dos assentamentos rurais é essencial o entendimento do todo, as conseqüências que são geradas na economia, na cultura, no ambiente, na sociedade, no meio tecnológico, na política e na história, ou seja, na organização espacial de Candiota.

\section{METODOLOGIA SISTÊMICA APLICADA EM ASSENTAMENTOS RURAIS}

Visto a parte teórico-conceitual da metodologia sistêmica em Bertalanffy (1975), Morin (1977) e Diniz (1984) percebe-se o grande número de variáveis que podem ser averiguadas. Aqui se discutirão os elementos que fazem parte do processo de alteração socioeconômica e territorial que os assentamentos rurais provocaram na organização do espaço em Candiota - RS.

Devido o município de Candiota estar situado na Campanha Gaúcha, região onde predominam as grandes propriedades e a monocultura, o estudo do processo histórico de ocupação do Rio Grande do Sul é fundamental para desvendar a estrutura fundiária existente, juntamente com as atividades agrícolas que são praticadas nela e analisar as desigualdades socioeconômicas entre a sociedade.

A verificação dos impactos da modernização no campo, a partir da década de 1960 é fundamental no estudo dos movimentos sociais, impulsionado pelos aumentos dos financiamentos agrícolas e do processo de integração agropecuária-indústria, a concentração de renda e da terra se agravou, causando o aumento do êxodo rural e conseqüentemente, a diminuição ou desaparecimento das pequenas propriedades em alguns espaços rurais. A respeito sobre a modernização dos campos gaúchos, Tambara (1985, p.62) adverte que teve como conseqüência "a expulsão de milhares de agricultores, configurando a cristalização de focos de movimentos sociais reivindicatórios, como é o caso dos agricultores semterra" Esse processo de aglutinação das pequenas propriedades por grandes empresas agrícolas ou por grandes fazendeiros gerou o início do conflito por terras para famílias sem propriedades rurais.

A análise dos assentamentos rurais e suas consequiências para o município e para os assentados são verificadas na redistribuição fundiária com o processo de colonização de áreas antes desabitadas, trazendo melhoria na infra-estrutura local, bem como a oportunidade da melhoria de vida das famílias assentadas e de outros agricultores. Esse processo de ocupação também revela as transformações no ecossistema natural, que deve ser avaliado, pois onde há a ação antrópica existe a alteração do espaço natural.

Dessa forma, a análise sistêmica das alterações dos assentamentos rurais no município de Candiota envolveu diversos fatores e elementos a serem estudados, conforme mostra a Figura 4.

\section{PROCEDIMENTOS METODOLÓGICOS}

Para a realização da pesquisa seguiram-se etapas. Primeiramente, foi feita uma revisão bibliográfica acerca dos assuntos a serem estudados como metodologia sistêmica, questão agrária, processo de evolução da ocupação do Rio Grande do Sul, assentamentos rurais e a territorialização do espaço, ou seja, a criação de uma base teórico-conceitual a fim de fundamentar o debate proposto neste artigo.

Em seguida, a pesquisa se baseou na abordagem quantitativa na busca de dados estatísticos e informações referentes ao município de Candiota, junto ao Instituto de Brasileiro de Geografia e Estatística - IBGE, Fundação de Economia e Estatística - FEE, Instituto Nacional de Colonização

Sociedade \& Natureza, Uberlândia, 20 (1): 125-137, jun. 2008 
e Reforma Agrária - INCRA e Prefeitura Municipal de Candiota. As informações dos assentamentos rurais de Candiota foram coletadas junto a EMATERCandiota e EMATER-Bagé. Conforme Organização das Nações Unidas para Agricultura e Alimentação FAO / INCRA (1997, p.17) "a análise global de uma região deve iniciar pela coleta e tratamento dos dados já existentes". Aqui se incluem documentos históricos, estatísticos e cartográficos existentes em uma primeira tentativa de correlacionar as diferentes variáveis.

A pesquisa junto ao município de Candiota para a coleta de dados sobre estrutura fundiária, assentamentos rurais, tipos de produções agrícolas, educação, saúde, infra-estrutura em geral, segurança, assistência técnica e outros indicadores socioeconômicos foi realizada por meio de trabalhos de campo. Essa etapa da investigação baseou-se na pesquisa qualitativa, com a coleta de dados através de entrevistas semi-estruturadas, junto a informantes qualificados de diferentes setores da sociedade, para a captação de informações sobre as mudanças ocorridas após a inserção dos assentamentos rurais no município de Candiota, além de entrevistas em dois assentamentos rurais: no primeiro assentamento criado no município em 1989, e no último assentamento criado em 2002.

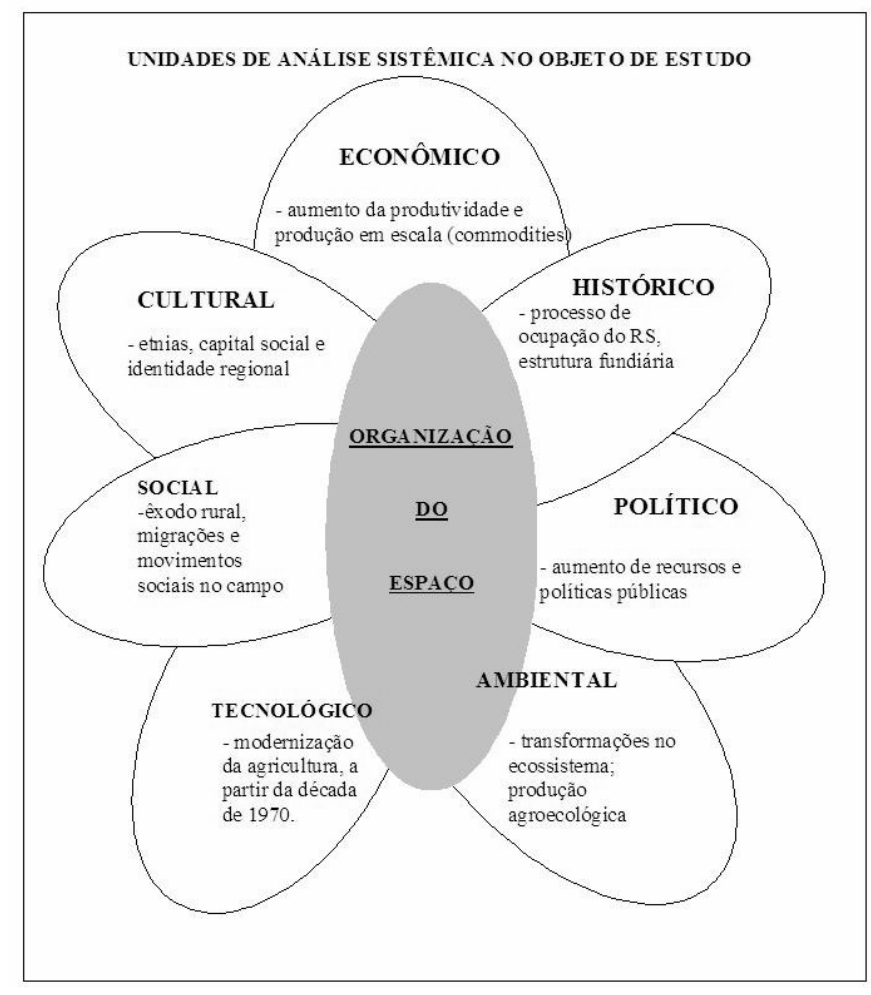

Figura 4 - Unidades de análise sistêmica no objeto de estudo. Organização: Flamarion Dutra Alves.

A escolha dessa etapa da pesquisa em ser de forma qualitativa teve, como princípio, a riqueza de detalhes adquiridos em entrevistas não estruturadas, a opção do informante em relatar o que sente naquele momento, não ficando restrito a opções prédeterminadas. A respeito da principal característica da pesquisa qualitativa (PATTON, 1986 apud ALVESMAZZOTTI e GEWANDSZNAJDER, 1998, p.131) afirmam que:

é o fato de que estas seguem a tradição 'compreensiva' ou interpretativa[...]estas 
pesquisas partem do pressuposto de que as pessoas agem em função de suas crenças, percepções, sentimentos e valores e que seu comportamento tem sempre um sentido, um significado que não se dá a conhecer de modo imediato, precisando ser desvelado.

Desse modo, "o processo de pesquisa qualitativa não admite visões isoladas, parceladas, estanques. Ela se desenvolve na interação dinâmica retroalimentando-se, reformulando-se constantemente" (TRIVIÑOS, 1987, p.137). Sendo de ordem qualitativa supõe o contato direto e contínuo do pesquisador com o ambiente e a situação que está sendo investigada por um trabalho intensivo de campo, para isso buscou-se fazer entrevistas com representantes de cada elemento ou unidade do sistema propostos na pesquisa.

O material obtido nas coletas de dados nessas pesquisas é predominantemente descritivo e rico em descrições de pessoas, citações, acontecimentos, incluindo transcrições de entrevistas e depoimentos. Citações são freqüentemente usadas para subsidiar uma afirmação ou esclarecer um ponto de vista, nesse caso todos os dados da realidade são importantes (LÜDKE \& ANDRÉ, 1986).

Para a coleta das informações em pesquisas qualitativas Triviños (1987) ressalta que a entrevista semi-estruturada é um dos principais meios que o investigador dispõe. Conforme esse mesmo autor, a entrevista semi-estruturada é entendida como:

[...] aquela que parte de certos questionamentos básicos, apoiados em teorias e hipóteses, que interessam à pesquisa, e que, em seguida, oferecem amplo campo de interrogativas, fruto de novas hipóteses que vão surgindo à medida que se recebem as respostas dos informantes. Desta maneira, o informante, seguindo espontaneamente a linha de seu pensamento e de suas experiências dentro do foco principal colocado pelo investigador, começa a participar na elaboração do conteúdo da pesquisa (TRIVIÑOS, 1987, p.1[6]).
A utilização de entrevistas semi-estruturadas para a obtenção de dados mais precisos é o procedimento adotado nesta investigação. Conforme Gil (1999), a entrevista pode ser definida como uma técnica onde o investigador apresenta-se frente ao investigado e lhe formula perguntas, com o objetivo de obter os dados que interessam à pesquisa, sendo esta uma das técnicas mais utilizadas no âmbito das ciências sociais.

A respeito do número de entrevistados, a rigor, não existe necessidade de definir uma amostra, porque o que importa é o significado de uma informação para a situação avaliada e não a quantidade de informantes que repetem essa mesma informação ou o número de vezes em que ela aparece. Anexar transcrições completas de parte das entrevistas, para que o leitor possa ter acesso ao chamado "material bruto" e tirar suas conclusões, também pode funcionar como estratégia a ser empreendida nessa mesma direção (DUARTE, 2002).

Foram realizadas entrevistas semiestruturadas a profissionais de órgãos públicos de assistência técnica (EMATER de Candiota), Secretaria de Educação, Secretaria de Saúde, Ação Social e Meio Ambiente, Cooperativas dos Assentados da Reforma Agrária e com o ex-Prefeito que assumiu no primeiro ano de emancipação e governou por oito anos o município de Candiota. Essas entrevistas visam consultar as iniciativas tomadas junto aos assentamentos rurais, e identificar as mudanças ocorridas no sistema socioeconômico municipal após a implantação desses.

As entrevistas com os agricultores assentados visaram contemplar as informações em relação às mudanças na vida de cada indivíduo após a reforma agrária, e quais mudanças foram significativas na infra-estrutura, culturas agrícolas e no cenário passado, mencionando as condições atuais e as perspectivas para os assentamentos rurais no município.

Sociedade \& Natureza, Uberlândia, 20 (1): 125-137, jun. 2008 


\section{OS RESULTADOS DA ABORDAGEM SISTÊMICA EM ASSENTAMENTOS RURAIS}

Analisando os resultados obtidos de forma sistêmica constatou-se a inter-relação de diversos elementos que são responsáveis pela organização espacial de Candiota.
O processo histórico de ocupação territorial do município foi fundamental apra que se estabelecesse um padrão fundiário extremamente concentrador e desigual, culminando numa forte desigualdade social, econômica e cultural. O gráfico 1 mostra a evolução fundiária em Candiota.

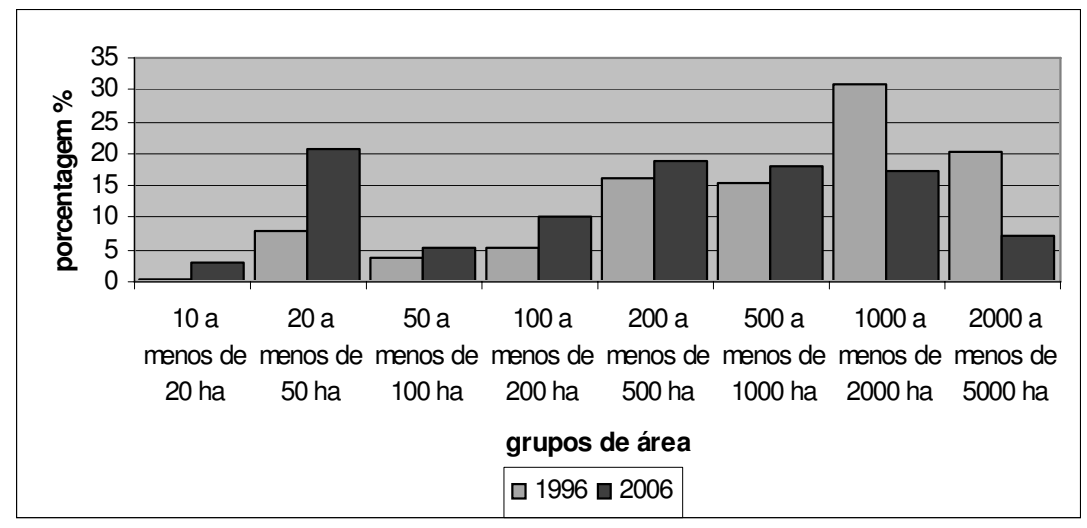

Gráfico 1. Porcentagem da área ocupada por estratos em Candiota 1996 -2006 ${ }^{1}$

Fonte: Censo Agropecuário do IBGE 1995/96 e levantamento na Prefeitura de Candiota, 2006. Organização: Flamarion Dutra Alves

Verifica-se uma queda na concentração fundiária, com a implementação dos 25 assentamentos rurais, as propriedades rurais acima de 500 hectares, em 1996, representavam 67\% da área municipal. Em 2006, as propriedades com mais de 500 hectares somam $32 \%$ da área municipal. Isso demonstra que o minifúndio e a pequena propriedade ganharam mais destaque na organização territorial do município, levando mais serviços e infra-estrutura ao espaço rural, que antes, devido à baixa densidade demográfica não tinha população suficiente para reivindicar os serviços básicos de um município.
Conforme a classificação do INCRA, em relação ao tamanho das propriedades rurais, ficou estabelecido que no município de Candiota, o módulo rural equivale a 28 hectares, ou seja, qualquer propriedade que tenha até 28 hectares é considerada como minifúndio, de 1 até 4 módulos corresponde a pequena propriedade. Assim, de 28 a 111 hectares é pequena propriedade,de 4 até 16 módulos, ou seja, de 112 a 447 hectares se classifica como média propriedade, e acima desse valor de 16 módulos é considerada grande propriedade. No caso de Candiota a grande propriedade corresponde a qualquer propriedade acima de 447 hectares (Tabela 1).

\footnotetext{
1 Os dados da estrutura fundiária foram coletados na Prefeitura de Candiota, referentes ao ano de 2006, estes dados são baseados no mesmo cadastro do Censo Agropecuário do IBGE.
} 
A metodologia sistêmica na geografia agrária: um estudo sobre a territorialização dos assentamentos rurais Flamarion Dutra Alves, Vicente Celestino Pires Silveira

Tabela 1. Estrutura fundiária em Candiota conforme a classificação do INCRA, 2006

\begin{tabular}{cccccc}
\hline Classificação & Módulo Rural & $\mathbf{n}^{\mathbf{0}}$ de propriedades & $\mathbf{\%}$ & Área (ha) & $\mathbf{\%}$ \\
\hline Minifúndio & $<28$ ha & 1.145 & 75,18 & 21.568 & 19,93 \\
\hline Pequena Propriedade & $28-111$ ha & 207 & 13,60 & 10.974 & 10,15 \\
\hline Média Propriedade & $112-447$ ha & 128 & 8,40 & 29.536 & 27,30 \\
\hline Grande Propriedade & $>448$ ha & 43 & 2,82 & 46.115 & 47,62 \\
\hline TOTAL & & $\mathbf{1 . 5 2 3}$ & $\mathbf{1 0 0}$ & $\mathbf{1 0 8 . 1 9 3}$ & $\mathbf{1 0 0}$ \\
\hline
\end{tabular}

Fonte: Levantamento de dados na Prefeitura Municipal de Candiota, 2006.

Organização: Flamarion Dutra Alves

De acordo com a classificação do INCRA, mais de $75 \%$ das propriedades de Candiota são consideradas minifúndios (Gráfico 2), a maioria provenientes dos assentamentos rurais e menos de 3\% das propriedades são consideradas grandes. Em 2006, 1.145 propriedades pertencem à classe minifúndio, correspondendo a $75,18 \%$ dos estabelecimentos rurais e representando $19,93 \%$ da área ocupada. Isso representa, praticamente, todos os lotes dos assentamentos rurais, que ficam entre 20 a 28 hectares em média. Mesmo com esse reduzido espaço para poder produzir para subsistência e comercializar, os assentados conseguem com sua agricultura e pecuária familiar obter condições básicas para uma vida digna ${ }^{2}$, segundo os assentados entrevistados.

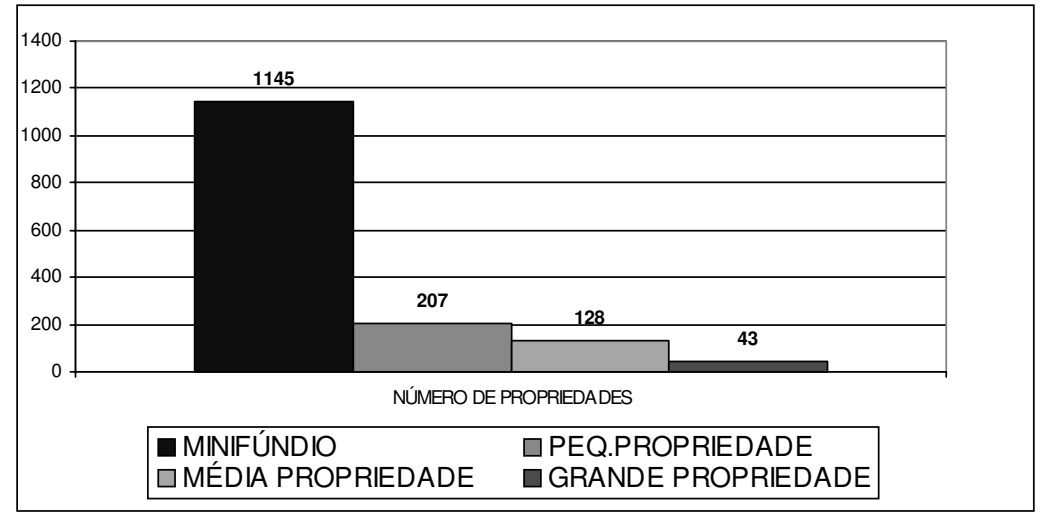

Gráfico 2. Número de propriedades conforme a classificação do INCRA no município de Candiota-RS

Fonte: Levantamento de dados na Prefeitura de Candiota, 2006.

Organização: Flamarion Dutra Alves

A área ocupada pelos 1.145 minifúndios em Candiota representa $19,93 \%$ da área total do município, ainda assim, a concentração fundiária existe e somando a área das médias e grandes propriedades percebe-se que as 171 propriedades ocupam $74,92 \%$ da área total do município. Essa classificação do INCRA mostra a evidente concentração de terras no município de Candiota, mesmo após a implementação de 25 assentamentos rurais (Gráfico 3) que ocupam 17.663 hectares, ou ainda, $16,3 \%$ da área total do município.

\footnotetext{
2 Segundo os assentados entrevistados, a existência de uma infra-estrutura básica, posse de um lote de terra para produzir para subsistência além de poder comercializar alguns de seus produtos, garantem uma vida digna para estes agricultores.
} 


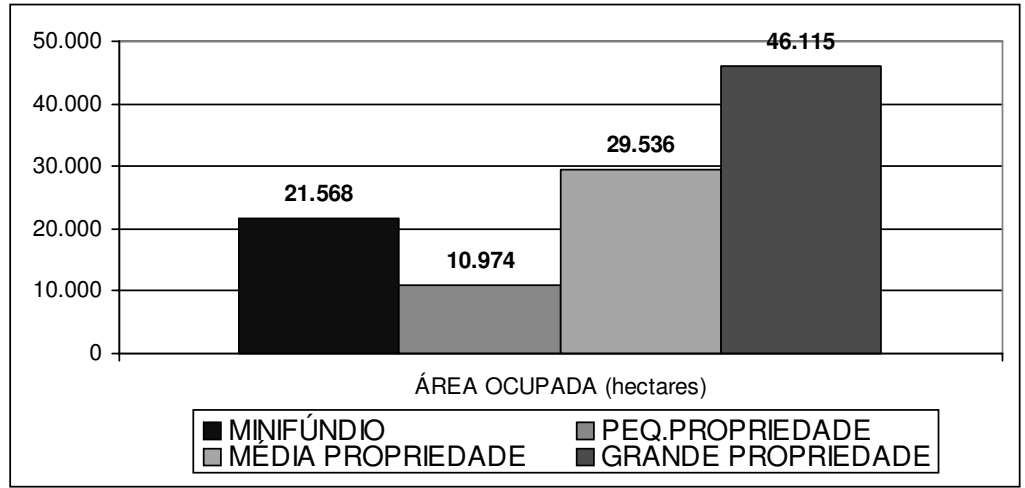

Gráfico 3. Área ocupada conforme a classificação do INCRA no município de Candiota - RS

Fonte: Levantamento de dados na Prefeitura de Candiota, 2006.

Organização: Flamarion Dutra Alves

Houve um aumento nas propriedades rurais com menos de 100 hectares no período estudado, passando de $72 \%$ em 1996 para $88 \%$ do total, ou seja, em 1996 eram 291 propriedades familiares que passaram a ser de 1.336 propriedades, provocando um acréscimo nos estabelecimentos de agricultura familiar no município. Esse crescimento da população no meio rural de Candiota trouxe algumas consequiências para esse espaço. A participação dos agricultores familiares no conjunto da economia do município aumentou, trazendo incrementos nas políticas públicas de crédito e financiamento aos agricultores familiares.

Esse aumento de capital circulante nessa população rural trouxe benefícios não somente a eles, mas também a toda organização espacial de Candiota, pois o dinheiro também é consumido no espaço urbano como em lojas, supermercados, serviços em geral, transporte, etc, ou seja, todo investimento dos órgãos públicos na estruturação e consolidação dos assentamentos rurais é revertido em melhorias na infra-estrutura rural, acréscimo do capital circulante no espaço urbano, obtenção da função social da terra com o assentamento de famílias, diversificação da produção rural com os agricultores familiares, colonização e reformulação agrária do território com a diminuição da concentração fundiária.

As dificuldades iniciais das famílias assentadas em Candiota em relação a uma infra- estrutura social básica eram precárias, como a criação de estradas e manutenção das existentes, ausência de eletricidade, serviços de saúde e educação, além da carência de recursos financeiros e políticas públicas para atender as questões de produção para essa população. Estes foram alguns dos motivos para que os assentamentos rurais não pudessem, em um primeiro momento, produzir para comercialização e obtenção de renda.

Uma alternativa agrícola para as condições climáticas da região é a produção de sementes de hortaliças e leguminosas (olerícolas). Várias empresas têm como fornecedores os agricultores familiares dos assentamentos rurais. Através da organização de uma Cooperativa Regional dos Agricultores Assentados (COOPERAL), criada em 1992, foram feitos contratos entre empresas de sementes olerícolas e assentados, na tentativa de geração de renda e desenvolvimento econômico.

Cinco grandes empresas de sementes Agroeceres, Hortec, Isla, Agroflora, Topseed trabalham de forma convencional com utilização de insumos químicos na região, inclusive a Isla tem uma unidade de produção em Candiota na qual boa parte dos agricultores que produzem para essas empresas é oriunda dos assentamentos rurais.

Em um encontro regional de assentados no final de 1996, discutiu-se uma alternativa para romper 
com a forma convencional de produção das sementes, uma forma que não se utilizasse insumos químicos e que não tornasse o agricultor dependente de produtos químicos. Neste momento, em torno de 35 produtores de Hulha Negra e Candiota trabalhavam dessa forma. No ano de 1997 surge a Bionatur sementes agroecológicas, começando um novo trabalho com 12 famílias de Hulha Negra e de Candiota. Num primeiro momento, a forma de produção foi de caráter experimental, onde não se teve uma questão de mercado bem constituída, porém, os resultados foram satisfatórios.

Hoje a demanda, a procura por produtor é muito maior do que a capacidade que a Bionatur tem de congregar, são mais de 120 produtores incorporados aos municípios de Candiota e Hulha Negra, que produzem mais de 50 variedades de sementes.

Desse modo, existem em Candiota duas linhas de produção de sementes, as que optam pela forma tradicional de produção, onde há mais empresas trabalhando nessa linha e os que escolhem pela forma agroecológica vinculada à cooperativa e dentro dos ideais do Movimento dos Sem-Terra - MST.

Outra atividade que predomina nos assentamentos é a pecuária leiteira, por melhor se adaptar a região da Campanha e também pela geração de renda constante, conforme Navarro (1999, p.24) "A produção de leite ao menos traz a vantagem de uma renda permanente, em contraposição à renda sazonal da produção agrícola". A produção de leite nos assentamentos rurais em Candiota é repassada para a COOPERAL, que é transportada para uma grande fábrica de laticínios da região Sul do Estado.

Nesse sentido, as duas formas de renda mais significativas nos assentamentos em Candiota são as produções de sementes de hortaliças e leguminosas, na qual se dividem nas formas tradicionais e agroecológicas, e a outra geração de renda significativa é a pecuária leiteira por meio da cooperativa dos assentados.

\section{CONSIDERAÇÕES FINAIS}

Analisando o aspecto fundiário do município, a implementação dos assentamentos rurais gerou um maior dinamismo no espaço rural, a criação de vários minifúndios exigiu a construção de estradas que interligassem os assentamentos, o aumento na rede de energia elétrica, a necessidade de ter um transporte coletivo que ligasse o meio rural com a sede do município, a instalação de postos de saúde para a população rural, criação de escolas, ou seja, a construção de um espaço rural dinâmico.

Com as grandes propriedades que existiam no município de Candiota o espaço rural era dominado pela monotonia dos campos, o latifúndio pastoril caracterizado pela carência demográfica e socioeconômica que determinavaum espaço concentrador de renda e terra, não contribuindo para uma melhoria social, apenas agravando as desigualdades existentes no Rio Grande do Sul e no país.

O estudo realizado em Candiota revelou os impactos que os assentamentos rurais provocaram nos diversos segmentos do município. As dificuldades encontradas serviram como experiência para fortalecer o movimento e os assentados. Os êxitos das famílias assentadas servem de modelo para que a reforma agrária contemple outros espaços estagnados pelos grandes vazios demográficos, diminuindo as diferenças sociais, econômicas e fundiárias no Rio Grande do Sul e no Brasil.

Portanto, um projeto de assentamento ideal busca ajustar viabilidade econômica com sustentabilidade ambiental, integrando produtividade com desenvolvimento territorial, qualidade e eficiência.

O assentamento rural deve criar condições para que o modelo agrícola possa ser modificado, introduzindo uma maior preocupação com a distribuição de renda, a ocupação e o emprego rural. Possibilitando segurança alimentar, mantendo o meio ambiente em equilíbrio, e também que o homem do campo tenha acesso a direitos fundamentais, para que se consiga obter um desenvolvimento sem desigualdades sociais.

Sociedade \& Natureza, Uberlândia, 20 (1): 125-137, jun. 2008 


\section{REFERÊNCIAS}

ACKOFF, R.F. Games, Decisions and Organization.

General Systems, York, n.4, p.145-150, 1959.

ALVES-MAZZOTTI, A. J. ; GEWANDSZNAJDER, F. O método nas ciências naturais e sociais: pesquisa quantitativa e qualitativa. São Paulo: Pioneira, 1998.

BERTALANFFY, L. von. Teoria geral dos sistemas. 2. ed. Tradução de Francisco M. Guimarães. 2.ed. Petrópolis: Vozes, 1975.

DINIZ, J. A. F. Geografia da Agricultura. São Paulo: DIFEL, 1984.

DUARTE, R. Pesquisa qualitativa: reflexões sobre o trabalho de campo. Cadernos de Pesquisa, São Paulo, n.115, p.139-154, 2002.

FAO - INCRA. Análise diagnóstico de sistemas agrários. Guia metodológico. Brasília: PCT INCRA/ FAO (UFT/BRA/051/BRA), 1997.

GIL, A. C. Métodos e técnicas de pesquisa social. 5. ed. São Paulo: Atlas, 1999.

LUDKE, M. ; ANDRÉ, M.E.D.A. Pesquisa em educação: abordagens qualitativas. São Paulo: EPU, 1986.

MORIN, E. O método: a natureza da natureza. Lisboa: Europa-América, 1977, v.1.

TAMBARA, E. RS: modernização \& crise na agricultura. 2.ed. Porto Alegre: Mercado Aberto, 1985.

TRIVIÑOS, A.N.S. Introdução à Pesquisa em Ciências Sociais: A pesquisa qualitativa em educação. São Paulo: Atlas, 1987. 